Portland State University

PDXScholar

1990

\title{
Speechreading ability in elementary school-age children with and without functional articulation disorders
}

Barbara L. Habermann

Portland State University

Follow this and additional works at: https://pdxscholar.library.pdx.edu/open_access_etds

Part of the Speech and Hearing Science Commons

Let us know how access to this document benefits you.

\section{Recommended Citation}

Habermann, Barbara L., "Speechreading ability in elementary school-age children with and without functional articulation disorders" (1990). Dissertations and Theses. Paper 4087.

https://doi.org/10.15760/etd.5971

This Thesis is brought to you for free and open access. It has been accepted for inclusion in Dissertations and Theses by an authorized administrator of PDXScholar. Please contact us if we can make this document more accessible: pdxscholar@pdx.edu. 
AN ABSTRACT OF THE THESIS OF Barbara $L$. Habermann for the Master of Science in Speech Communication: Speech and Hearing Sciences presented April 6, 1990.

Title: Speechreading Ability in Elementary School-Age Children with and Without Functional Articulation Disorders.

APPROVED BY THE MEMBERS OF THE THESIS COMMITTEE :

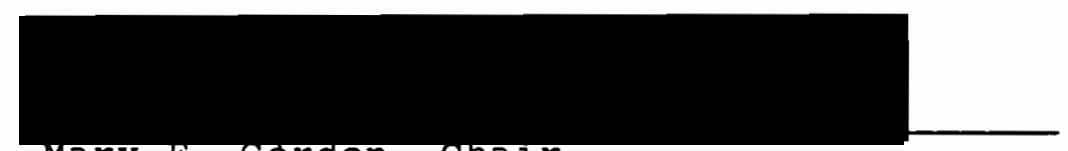

Mary E. Ggraon, chair
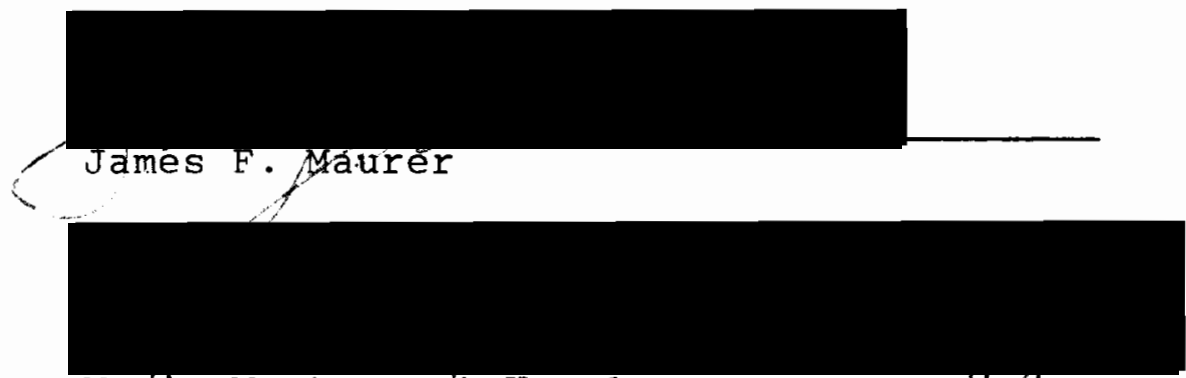

Maria Montserrat-Hopple

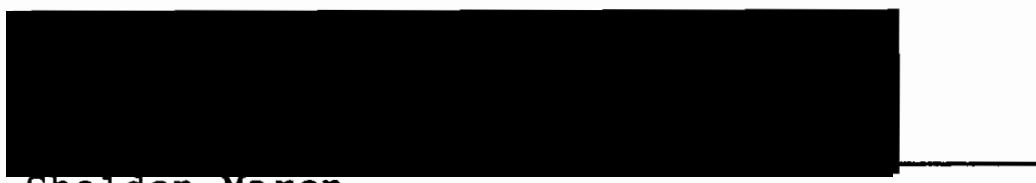

Sheldon Maron

The purpose of this study was to compare the speechreading abilities of elementary school-age children with mild to severe articulation disorders with those of children with normal articulation. Speechreading ability, as determined by a speechreading test, indicates how well a person 
recognizes the visual cues of speech. Speech sounds that have similar visual characteristics have been defined as visemes by Jackson in 1988 and can be categorized into distinct groups based on their place of articulation. A relationship between recognition of these visemes and correct articulation was first proposed by Woodward and Barber in 1960. Dodd, in 1983, noted that speechread information shows a child how to produce a sound, while aural input simply offers a target at which to aim.

Fifty subjects participated in this study, 25 children with normal speech, and 25 children with functional articulation disorders. All were chosen from the greater Portland Metropolitan area. To qualify for inclusion in this study, all subjects had normal vision, hearing, and intelligence. The experimental group was selected first and the control group was then individually age-matched to this group within \pm 6 months. A11 subjects wore headphones emitting $65 \mathrm{~dB}$ SPL of masking noise while being given the craig Lipreading Inventory which was administered live by the investigator. Statistical analysis using a one-tailed t-test for independent means was conducted to compare the groups. A statistically significant difference beyond the .05 level of confidence was determined, with the children in the control group performing better. These results indicate that children with articulation disorders do not recognize the visual speech cues as well as their normal speaking peers. These results agree with those of a similar study done by 
Russell in 1971. The implications of this study suggest that recognition of the visual speech cues can contribute to correct speech production and perhaps teaching speechreading along with articulation treatment would be helpful for some children with functional articulation disorders. 
SPEECHREADING ABILITY IN ELEMENTARY SCHOOL-AGE CHILDREN WITH AND WITHOUT FUNCTIONAL ARTICULATION DISORDERS

\section{by}

BARBARA L. HABERMANN

A thesis submitted in partial fulfillment of the requirements for the degree of

MASTER OF SCIENCE

in

SPEECH COMMUNICATION :

SPEECH AND HEARING SCIENCES

Portland State University

1990 
TO THE OFFICE OF GRADUATE STUDIES:

The members of the Committee approve the thesis of Barbara L. Habermann presented April 6, 1990.

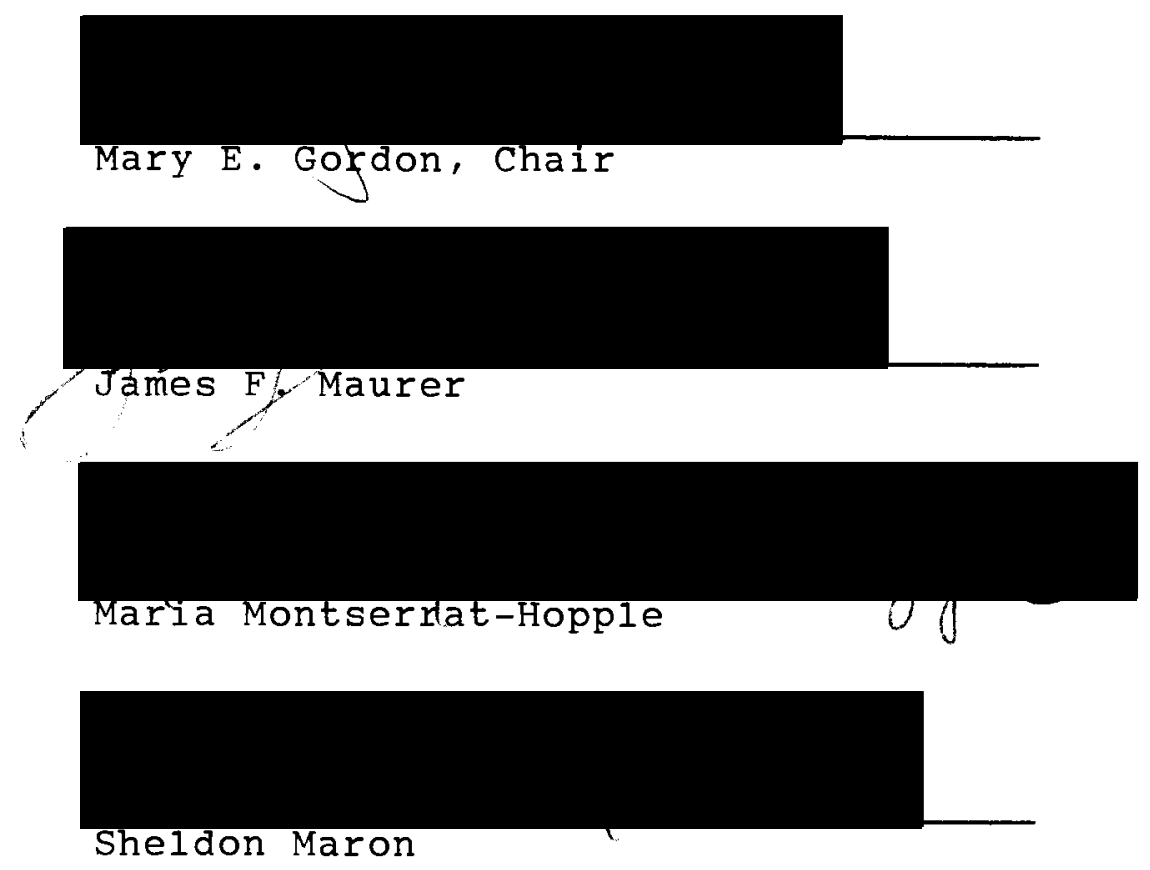

APPROVED :

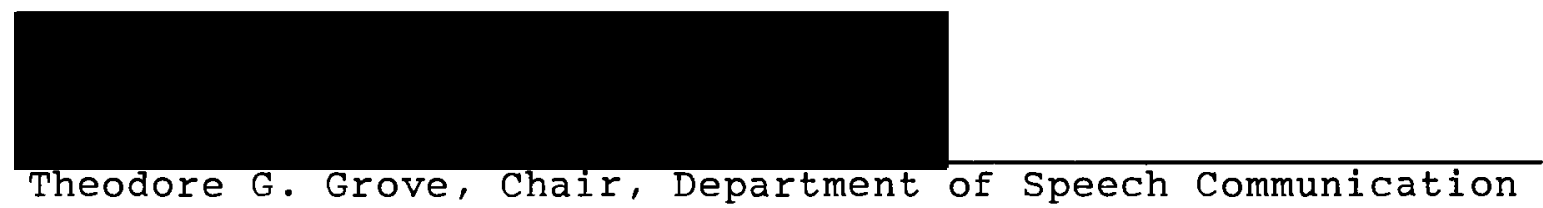

c. William Savery, Interim vicoprovost for Graduate studies and Research 


\title{
ACKNOWLEDGMENTS
}

I would like to thank the members of my committee:

\author{
James F. Maurer \\ Maria Montserrat-Hopple \\ Sheldon Maron
}

for all their help and encouragement.

Special appreciation goes to Mary E. Gordon, my advisor and chair of this committee for all her excellent input, willingness to give of her time, and her eye for detail.

I also want to thank my husband Bob and my daughter Megan for all their love and support. 
TABLE OF CONTENTS

PAGE

ACKNOWLEDGMENTS . • . . . . . . . . . . . . . . . . iii

LIST OF TABLES . . . . . . . . . . . . . . . . . vi vi

CHAPTER

I INTRODUCTION AND STATEMENT OF PURPOSE $\cdot$. . . 1

Introduction . . . . . . . . . . . . . 1

Statement of Purpose . . . . . . . 3

il ReView of the literature . . . . . . . . . . 4

Characteristics of Visual Speech . . . . 4

Visual Recognition of Speech

by Adults

Visual Recognition of Speech

Summary

by Children

Visual Impairment and Speech Production .

Speechreading Tests . . . . . . . . 18

II METHODS . . . . . . . . . . . . . 22

Subjects . . . . . . . . . . . . 22

Instrumentation . . . . . . . . . 23

Procedures . . . . . . . . . . . . 24

Screening Procedures

Experimental Procedures

Training and Reliability

Procedures

Scoring and Data Analysis... . . . 28 
IV RESULTS AND DISCUSSION

Results. . . . . . . . . . . . . 29

Discussion . . . . . . . . . . 32

V SUMMARY AND IMPLICATIONS . • . . . . . . . . . 37

Summary • • • • • • . • . • • • . 37

Implications . . . . . . . . . . . 38

Research

Clinical

REFERENCES

APPENDIX

A INTRODUCTORY LETTER - . . . . . . . . . . . . 44

B CONSENT FORM FOR SUBJECTS AND CONTROLS . • . . 45

C CONSENT FORM FOR SUBJECTS OVER 7 YEARS OF AGE . . . . . . . . . . . . . . . . 46

D GRAHAM-FIELD EYE CHART • . • . • . • • . • • . . 47

E CRAIG LIPREADING INVENTORY TEST FORM • • • • • 48

F ANSWER SHEET FOR FORM "A" OF THE CRAIG

LIPREADING INVENTORY • • • • • • . • • 


\section{LIST OF TABLES}

TABLE

PAGE

I Visible Speech Movements . . . . . . . . . 6

II Raw Test Scores for Forms "A" and "B" of the CRAIG . . . . . . . . . . . . . .

II Mean Scores and Standard Deviations for

Forms "A" and "B" of the CRAIG . . . . . .

IV Raw Scores for the CRAIG Lipreading Inventory . . . . . . . . . . . . . 30

V Mean Speechreading Scores by Age Group . . . .

VI Mean Scores, Standard Deviations, and $\underline{t}-\mathrm{values}$ for Combined Ages . . . . . . . . . .

VII Pearson $\underline{r}$ Coefficient of Correlation Between

Age and Speechreading Skill . . . . . . .

VII Coefficient of Determination . . . . . . . . . 
CHAPTER I

INTRODUCTION AND STATEMENT OF PURPOSE

\section{INTRODUCTION}

As Weiss, Gordon, and Lillywhite (1987) have reported, approximately $70 \%$ of speech disorders are articulation disorders. Speech-language pathologists work with many children who have articulation disorders and the goal with these children is to remediate them as quickly as possible and to instil1 carryover.

It has been noted that many visually handicapped children, who are not hearing impaired, have articulation disorders (Mills, 1983). In addition, most researchers agree that even very young infants can perceive differences between sounds, by using both vision and audition (Spelke, 1976). This brings up the question of the relationship between visual cues of speech and correct speech production. Most approaches to remediating articulation disorders do not include teaching visual discrimination of speech through speechreading or other methods, but rather place emphasis on auditory sensory input. However, some consonants are identified primarily by their place of articulation, information which is best supplied visually, and perhaps certain articulation errors are related in part to poor visual perception of these phonemes. 
Training in visual perception through teaching speechreading or through other methods, therefore, could be an appropriate and effective technique to use in remediation of some articulation disorders.

As a class project, Russell (1971) conducted a study comparing the speechreading abilities of children with normal articulation to children with articulation disorders. She found a significant difference between the two groups, with the articulation-disordered group demonstrating considerably poorer speechreading ability. These results lend some support to the proposition that visual discrimination training may be as helpful in treatment of certain articulation disorders as auditory discrimination training is considered to be.

Although no research has been done using speechreading training for remediation of articulation disorders, a great deal of research into the importance of visual recognition of speech for the hearing impaired has been done using normally hearing subjects. Before improvement of speechreading skills could be included in the remediation of articulation, however, it would first have to be determined if a child had a deficit in this area. One of the ways to assess visual discrimination of speech is by using a speechreading test. For the purposes of this study, speechreading and lipreading will be defined as the recognition of speech through visual interpretation of lip and facial movements. 
STATEMENT OF PURPOSE

The purpose of this study was to compare the speechreading ability of elementary school-aged children with mild, moderate, or severe functional articulation disorders to children with normal articulation in order to determine if the two groups of children demonstrate the same degree of visual speech discrimination.

The null hypothesis tested was:

School-aged children diagnosed with mild, moderate, or severe articulation disorders will not show poorer speechreading ability than normally articulating children when evaluated using a speechreading test. 
CHAPTER II

REVIEW OF THE LITERATURE

CHARACTERISTICS OF VISUAL SPEECH

The perception of speech is not limited to auditory comprehension, as visual perception can also affect the way it is heard in noisy or quiet settings (Dodd, 1977). Many authors have researched the effect visual information has on speech perception. MacDonald and McGurk (1978) state that although hearing provides exact information about the manner of articulation, it is vision that offers more precise information about the place of articulation. While the information received from speechreading is not an essential part of speech comprehension, the availability of such information could be used to the advantage of the listener in regard to speech perception and may, along with hearing, influence speech production as well. According to Dodd (1987), the relationship between visual and aural speech is unique and exists within the context of language.

Speech sounds, or phonemes, that have similar visual characteristics have been defined by Jackson (1988) and others as visible phonemes or visemes. These visemes can be placed into distinct groups based on their place of articulation. However, according to Jackson, the grouping of 
these visemes is not an easy task, as several factors in addition to the visual characteristics can influence the perception of the visemes, such as the dialect and physical characteristics of the speaker, lighting, and distance and angle of observation. In her review of seven studies using consonant viseme groups, Jackson found agreement among researchers for grouping some of the consonant phonemes, but several of the remaining phonemes remain unassigned to groups. The viseme groups are 1isted below. It is visemes that are taught in speechreading.

Assigned Viseme Groups

$$
\begin{aligned}
& / \mathrm{p}, \mathrm{b}, \mathrm{m} / \\
& / \mathrm{f}, \mathrm{v} / \\
& / \theta, \mathrm{x} / \\
& / \mathrm{J}, 3, \mathrm{t}, \mathrm{d} / \mathrm{g} / \\
& / \mathrm{w}, \mathrm{r} /
\end{aligned}
$$

\section{Unassigned Visemes}

$/ t, d, s, z, j, k, n, g, 1, h /$

speechreading is the ability to recognize speech without the benefit of sound. Jeffers and Barley (1971) defined a speechreading movement as one that has a "recognizable motor pattern, usualiy common to two or more speech sounds" (p. 42). While there are 14 speechreading movements which can be perceived under ideal viewing conditions, only 4 of these movements (1-4), can be considered reliable (Table I). Although the ability to speechread may come more naturally to some, the skill can be improved through instruction (Crawford, Dancer, and Pittenger, 1986). 
TABLE I

VISIBLE SPEECH MOVEMENTS

Speech Movement

Sound Produced

1. Lip to teeth $\ldots \ldots \ldots \ldots \ldots \ldots$ /f, $/$ /

2. Lips puckered, narrow opening ... /w, r,u, v,ov, $32 /$

3. Lips together ........... /p,b,m/

4. Tongue between teeth $\ldots \ldots \ldots \ldots / \theta, z /$

5. Lips forward ............./S,3,ts, d3/

6. Lips back, narrow opening ....../j,i,I,eI, $\wedge$, , /

7. Teeth together $\ldots \ldots \ldots \ldots \ldots \ldots / s, z /$

8. Tongue up and down $\ldots \ldots \ldots \ldots \ldots / t, d, n, 1, n t, n d, 1 d /$

9. Tongue back ................. /k,g,g/

10. Lips rounded, moderate opening .. / / /

11. Lips relaxed, moderate opening .. / $/ \varepsilon, x, a /$

12. Lips relaxed, moderate opening

to 1 ips puckered, narrow

opening ................... /av/

13. Lips rounded, moderate to

lips back, narrow ............ I I /

14. Lips relaxed, moderate to

lips back, narrow ............. /aI/

When teaching an individual to recognize the visemes, three types of instruction modalities are employed (Jeffers and Barley, 1971). The basic instruction in teaching speechreading is to have the students learn to recognize all visible speech movements and to use their eyes along with their ears when listening to a speaker. This type of instruction is usually given to adults who had normal hearing in their 
developmental years and who have an established knowledge of language, learned through auditory means. The second type of instruction is to teach the basic skill of speechreading in addition to vocabulary improvement. This type of instruction is usually taught to mainstreamed, moderate to severe hard-of-hearing children who understand the basic grammatical rules of language. The third type of instruction is the teaching of the skill while developing language through both speech and reading. This is the type of instruction for the profoundy deaf child (Jeffers and Barley, 1971).

\section{Visual Recognition of Speech}

\section{by Adu1ts}

The question of the value of these visemes to speech recognition has been addressed by many researchers. In a landmark study, Woodward and Barber (1960) noted that the differences between articulation and the visual ability to perceive these differences may be considered a basic level of speech perception. These authors proposed that visibility of phonemes is important to the function of articulation and a rank order of visibility can be established. A random order of 229 nonsense syllable pairs were selected as stimuli for their study. Of their 305 normally hearing adult subjects, 185 watched the presentation of these pairs on a film without sound, 65 subjects 1 istened to the soundtrack presentation only, and 55 subjects watched and listened to the presentation on film. The authors found that 44 of the syllable pairs could be visually contrasted and that these pairs 
were identified by place of articulation, 79 pairs were contrasted aurally, and 85 pairs needed both auditory and visual information to be contrasted. However, these authors contended that a weakness in their study may be the use of nonsense syllables, and perhaps speechreading is more than just a visual ability, but is influenced by meaningful speech and speech presented in larger units, such as words. This initial study has influenced many other studies in the same area.

Fisher (1968) investigated the confusion among visually identified consonants by testing 18 normally hearing adults' responses to the visual recognition of consonants in words, both in initial and final positions. However, Fisher deleted the correct response from the test form given the subjects in order to create confusion and to determine if the answers that were selected could be classified into groups. In initial position, Fisher found that voiced and voiceless consonants with the same place of production were often confused, as well as consonants with similar places of production. However, this was not the case in final position, where the confusion was more varied in general. Fisher attributed this to the final consonant being "predicted" by the subjects due to the preceding phonetic context.

Binne, Montgomery, and Jackson (1974) studied consonant recognition in 10 normally hearing adults using different conditions of signal-to-noise ratios when the consonants were presented both visually and aurally, visually only, and 
aurally only. Again, videotaped presentation was employed. Their results showed that, with masking noise, the scores from the auditory-visual tests indicated that vision made the most contribution when the confused phonemes differed by place of articulation. Also, all the subjects placed the consonants into distinct groups, again in regard to place of articulation, information which is best supplied visually. These results suggest that visual discrimination contributes greatly to correct identification of phonemes and may influence correct production as well.

Dodd and Campbel1 (1984) also conducted a study concerning the ability to code visual and auditory information, in order to determine if visual consonant confusion is due to processing differences between the two modes of speech perception. Adult subjects with normal hearing watched a television monitor with an experimenter saying one word at a time. All subjects were wearing headphones emitting white noise. The subjects were required to reproduce consonantvowel-consonant ( $\mathrm{CVC}$ ) words. The level of masking was determined when the subject was correct on 5 of 6 words. The subjects then watched the monitor and were asked to reproduce the words which were first seen and then heard, then to reproduce the words heard first and then seen. The only significant difference found was that all the subjects had more substitutions of voiced for voiceless consonants when the visual information was presented first, indicating that while 
auditory input was important for this feature it was not as important for identifying the other CVC words.

In his 1982 study, Haas assessed speechreading performance when the stimulus presented was predictable. He felt that perhaps the visual consonant confusion found in other studies was due to unpredictable verbal contexts. In order to determine their speechreading ability, 30 college students with normal hearing were selected for this study, and all viewed the Utley Speechreading Test (Utley, 1946) on videotape. The subjects were tested on their ability to identify words, phrases, and a conversation between a parent and child. Immediately after this test, the subjects were shown slides of nonsense words which they then had to identify. The words were presented a letter at a time, and then presented five more times with varying ranges of speeả. Haas found that the subjects who demonstrated the better speechreading abilities were able to recognize the nonsense words much more quickly even when the speed of the presentation was increased. He felt that as the predictability of the stimulus nonsense words increased, the identification task became easier even though the words were not actual English words. He noted that concession to predictability of the phonemes should be a consideration when assessing speechreading ability.

Kricos and Lesner (1982) also looked at consonant confusion among speechreaders. They chose 12 normal hearing adults and 6 different presenters. They wanted to assess the 
difference, if any, in the speechreading talents of their subjects when various "talkers" were used. Twenty-four consonants were presented using /a/C/a/ as the format. These authors found that the speechreading abilities of the subjects showed much variation across the different speakers, with 3 of the speakers being more difficult to speechread. They suggested this is an important finding as speechlanguage clinicians usually work one-to-one when either teaching speechreading or teaching correct placement in articulation treatment. If the clinician is not a good talker as far as lipreading presentation is concerned, then the teaching may not be effective.

other researchers have investigated whether this viseme confusion also occurs in the hearing impaired as the subjects for the Kricos and Lesner (1982) study all had normal hearing. In 1985 Owens and Blazek investigated the speechreading ability of both normal hearing and hearing impaired subjects. None of the subjects had received prior training in speechreading. The 5 hearing impaired adults and 5 normal hearing adults were given a silent videotaped presentation of the American English Medial Consonant Test (Dent, Huntington, and Schubert, 1982). The results of this study found that the responses for both groups were fundamentally the same in both visemes recognized and in total score. It was noted that when the vowel / $\mathrm{u} /$ was used, the recognizable visemes were limited to $/ \mathrm{p}, \mathrm{b}, \mathrm{m} /$ and $/ \mathrm{f}, \mathrm{v} /$. When the vowels $/ \wedge /$ and $/ \mathrm{i} /$ were used $/ t, d, s, z /$ emerged as a viseme group, but not 
$/ k, g, n, 1 /$, an effect that was reversed when the vowel /a/ was used. The authors noted that adults sharing an auditory language appear to share the same articulatory expectations of speakers, regardless of whether or not the 1 istener has a hearing impairment.

\section{Visual Recognition of Speech}

\section{by Children}

The question of whether infants also have visual speech expectations was explored by Dodd and Burnham (1988) in two separate experiments. In the first experiment, 21 full term, normal hearing infants aged 8 to 54 weeks were studied. The subjects were divided into three age groups of $2-4$ months, 5-7 months, and 8-12 months. The experimenters presented live spoken babble (e.g., ba, ba-ba), recorded audio-alone babble, live speechread-alone babble, and two silent presentations using both a doll and a wolf puppet. Each presentation was approximately 3 minutes in length.

The results of this study showed that the infants aged 2-4 months did not react to the speechread-alone stimulus by avoidance or protest, and indicated their acceptance of this form of communication by attending more to it than to the audio-alone presentation. Infants between 5 and 7 months were the most responsive in this experiment and these babies fell into two groups, those that were fascinated by the speechread-alone stimulus presentation and those that avoided it. This could suggest that children this age begin to become disturbed when speech is presented without vocalization. 
The final group of children, 8-12 months old, were both more aroused and showed more avoidance tendencies when the speechread stimulus was presented. Several of these infants also fingered the mouth of the doll during presentation of the speechread material, suggesting recognition that mouth movements were the salient aspect of the experiment. The researchers also found that the response to speechread information increased with age. In order to answer the question of whether this recognition between speech production and lip movements is learned through experience and is primary language specific, Dodd and Burnham (1988) conducted a second study .

In the experiment, 12 10-week old infants and 12 20week old infants were selected to watch live, side-by-side simultaneous presentations of both spoken and speechread material given in both English, the infants' native language, and Greek. Each presentation was 30 seconds in length. The results of the study showed that 8 of the 1210 -week old infants attended more to the speechreader using the English text than to the one using the Greek text. However, their attendance times varied greatly and no significant difference was found. In the 20 -week old group, 10 of the 12 subjects attended to the English speechread material more than the Greek speechread material and the preference scores showed a significant difference. This seems to suggest that children as young as 20 weeks of age can associate 1 ip movements to verbal speech within a familiar language context. 
Although these studies indicated that infants can discriminate speechread information, their perception of this information could not be tested.

Dodd (1987) investigated whether young children could recognize words from visual representation only, and therefore use the speechread input Iinguistically. Seventeen normal hearing children, aged 18 to 36 months, were selected from the nursery at Macquarie University. Prior to the experiment, the subjects became familiar with the researchers and all were trained to the task by learning to point to pictures of objects or animals when asked. During the experiment the subjects were told to watch the experimenter's face before pointing to each picture because sometimes the experimenter would "lose her voice." Two sets of 10 colored cards were used. The mean correct response when the speechread stimulus was given was 4.7 for the first set and 5.0 for the second set of pictures. These results suggest that young children are able to process speechread words and to use that information to identify pictures. None of the children in this study showed any reluctance in accepting the fact that a purely "lip read" presentation represented a word. Dodd further noted that this finding could mean that children not only reserve information about how words sound, but how they look as well, and that this knowledge could be valuable in phonological acquisition. 


\section{Summary}

In summary, these studies all agree that using speechreading to identify consonants can be valuable in regard to place of articulation, and in addition, if the stimulus being presented is familiar and meaningful to the listener, speechreading can be used to aid identification of words, for both adults and children. While the primary focus of many of these studies was to determine the value of speechreading and if this skill can be refined in order to help the hearing impaired, all but one of these studies used normal hearing subjects. The findings of these studies point out the importance that visual perception has in speech recognition. Perhaps accurate speechreading skill could also be a strategy used for correct speech production.

\section{VISUAL IMPAIRMENT AND SPEECH PRODUCTION}

As previously stated, place of articulation is perceived primarily through vision. Therefore it is logical to assume that a child or adult with a visual handicap, but no other impairment, would demonstrate articulation errors in regard to the feature of place. Several different studies have supported this assumption.

According to Elstner (1983), the sighted infant has developed visually learned speech patterns by the age of 6 months, while the visually handicapped infant does not have the opportunity to match visual and auditory stimuli. The blind child also babbles less than the sighted child, even 
when no other handicapping condition exists. In addition, he stated that blind children make more articulation errors in general than do sighted children.

In 1983 Mills made two predictions related to visual acuity and correct articulation. First, that to produce a sound correctly, a child must have both auditory and visual information available. Second, she proposed that because infants watch the mouth movements of speakers, visual information may be much more important during the period of speech development than has been realized. She selected three subjects for her study; two had normal vision and one was blind. All of the children were 2 years of age and their language development was normal. Mills had the subjects imitate words and also recorded samples of their spontaneous speech in order to analyze their articulation errors. She used the data collected from these subjects to test her predictions.

Mills investigated whether sighted children learn articulation motions they saw quicker and with more accuracy than those motions they could not see, whether they substituted within visual groups of sounds which she described as the sounds identified primarily by place of articulation, and if blind children substituted across visual groups and therefore displayed unique articulation errors. She only analyzed sounds in initial position because of the age of her subjects. The results of her study showed that the sighted children made fewer errors in words beginning with sound that 
are distinctive in regard to place of articulation, and the errors they did make were within visual groups of sounds. The blind subject in her study made more substitutions across all visual groups and these substitutions appeared to have no distinct pattern, while the production of other sounds not dependent on place was the same as the sighted children.

Doad (1983) reanalyzed data she had collected in a previous study in order to see if she would duplicate the results obtained by Mills. She had a spontaneous language sample from a 21-month old, normally developing child who was born without eyes. Dodd compared this sample, word-for-word, with a language sample of a sighted child. The results of her analysis showed that the sighted child was more likely to substitute a sound from the same visual group, while the blind child substituted sounds from differing visual categories. These results support Milis' findings. Dodd further stated that these results are not surprising, as speechread information shows a child how to produce a sound, while aural input simply offers a target at which to aim.

In summary, these studies, as well as ones defining visual speech, indicate that visual information is important for correct articulation of some sounds. When this information is absent, as it is for blind children, the result is both more and varied articulation errors in regard to place of articulation as compared to sighted children. The inability to recognize this visual information for children with 
normal sight may also be a contributing factor to misarticulations in these children.

\section{SPEECHREADING TESTS}

One purpose of formal speechreading tests is to assess a person's natural ability to identify visual speech cues. O'Neill and Oyer (1981) classified formal speechreading tests into two types, those that are administered face-to-face and those that use filmed presentation. Either of these types can be given with or without voice and may cover syllable, word, sentence, story recognition, or a combination of these stimuli. Each of these types of tests has specific advantages and disadvantages inherent in their design.

Face-to-face or "live" speechreading tests were used as early as 1951 (Berger, 1972), and many of these types of tests have since been developed. Live presentation has several advantages, the main one being that it is the most naturalistic in context and therefore should have the greatest validity (Berger, 1972). Many professionals in the field of aural rehabilitation prefer face-to-face presentation because of this. Also, the speaker often has the same dialect as the client, making the test material more familiar (Alpiner and McCarthy, 1987). The main disadvantage of this type of test is that live presentation is very difficult to control. The consistency of presentation can vary in regard to movement of the articulators, intonation, and rate of presentation every time the test is given. O'Neill 
and Oyer (1981) have stated that one of the most important aspects of administering a speechreading test is controlling the test conditions and they prefer taped presentation because of this factor.

While filmed tests do overcome the problem of inconsistency of presentation, they have other disadvantages. Berger (1972) noted that Nitchie probably developed the first filmed speechreading test in 1936. While these types of tests do provide consistent repetition of the test material, they do so in an unnatural context. Additional variables that must be controlled when using a prerecorded test include film quality and clarity, the size of the image on the screen, the length of time the image will be presented, and the time between presentations. Often these items are not taken into consideration when a test is selected (0'Neill and Oyer, 1981). In addition to the disadvantages of each specific type of speechreading test, the tests in general have received criticism.

Constructing a valid and standardized test of speechreading has proven to be a difficult task. Although many tests have been shown to be reliable in test-retest measures, to date, no standardized, widely accepted test exists. The problems in establishing standardization have occurred in finding the criterion for comparison to the speechreading test results. Intelligence test scores, silent reading ability, and educational achievement have all been thought to relate closely to speechreading ability, but research in 
these areas have not supported this assumption (Jeffers and Barley, 1971). It is possible that this is due to the many different factors, such as motivation, that can affect speechreading performance and the fact that the variables cannot always be controlled. In fact, Jeffers and Barley (1971) have noted that the facts seem to point to the conclusion that expert speechreaders are "born and not made." In addition to the problem of establishing standardization, the validity of speechreading tests has also been questioned. Filmed tests have proven to have poorer validity than face-to-face tests, and this could be due to the two-dimensional aspect of the test presentation (Berger, 1972). In addition, face-to-face tests report significantly higher scores when compared to filmed tests which cover the same type of material (Jeffers and Barley, 1971). Although no ideal test has been developed, formal speechreading tests are still one of the best ways to assess a person's ability to understand and identify visual speech. One of these tests, the Craig Lipreading Inventory (CRAIG) (Craig, 1964), was selected for this study.

Craig developed this test in 1964 for his study to assess the effect preschool training had on deaf children's lipreading and reading ability. He constructed his lipreading test by using 243 deaf children ranging in age from 6 years, 8 months to 16 years, 6 months. All of the children were residents of a school for the deaf and had been enrolled in a preschool training program (Craig, 1964). 
The CRAIG consists of 4 separate tests--2 word identification tests, and 2 sentence identification tests. Each word test contains 33 groups of 4 words, and each sentence test contains 24 groups of 4 similar sentences. The words and sentences are both pictured and written in order to negate any effect reading ability may have on the test results. The test is appropriate for children from the end of first grade to tenth grade (Jeffers and Barley, 1971). Craig (1964) designed his test to be given live, with or without voice, by one trained presenter. He stated that live presentation is more realistic and the use of only one presenter should reduce variability of stimulus presentation. The vocabulary covered by this test is one commonly used in kindergarten and first grade and is large enough in variety so that the lack of a few word concepts should not affect the test results (Jeffers and Barley, 1971). In establishing his test, Craig determined mental age for all of his subjects using the Leiter International Performance Scale, the WISC, or the Nebraska Test of Learning Aptitude, and O'Neill and Oyer (1981) have noted that a significant correlation between test results and mental age has been established. Although the CRAIG is subject to the same drawbacks of all speechreading tests, it is a very appropriate test for schoolage children. 


\section{CHAPTER III}

\section{METHODS}

\section{SUBJECTS}

The subjects for this study were chosen from 4 elementary schools in the greater Portland Metropolitan area. Fifty children (grades 1 to 5) were selected for two groups of 25 children each. The control group consisted of children with normal articulation. The experimental group consisted of children who had mild, moderate, or severe functional articulation disorders diagnosed by their public school speech-language pathologists and who were currently receiving articulation and/or language treatment. The mean age of the subjects in both groups was 8 years, 7 months. There were 16 boys and 9 girls in the control group and 20 boys and 5 girls in the experimental group. Socioeconomic status was not considered in subject selection. To be selected for this study, the subjects met the following criteria:

1. permission form signed by the parent or primary caregiver for the child to participate in the study (Appendices $\mathrm{A}-\mathrm{C})$;

2. 6 to 12 years of age;

3. normal or corrected vision as determined through administration of a standard vision screening using the Graham-Field Eye Chart (Appendix D); 
4. normal hearing acuity as determined by the administration of a bilateral pure tone hearing screening;

5. the entire school day spent in a regular classroom with no time in resource rooms; and

6. English as the primary language spoken.

The children for the experimental group were chosen first. Individuals in this group were then age-matched to within \pm 6 months with each of the control subjects.

\section{INSTRUMENTATION}

A portable audiometer, meeting the calibration standards using the ISO 1964 levels endorsed by ASHA, was used to administer a hearing screening to all subjects.

The Graham-Field Eye Chart, a standard vision testing instrument printed with the letter $E$ which decreases in size and faces either up, down, right, or left was used as the vision screening instrument for all subjects.

The CRAIG (Craig, 1964) was administered to all subjects. For this study, the first part of the CRAIG, the word recognition test, was used. Two forms of this test are available. Form "A" was chosen on the basis of the results of a pilot study done by this investigator. This part of the test has a multiple choice format, using words commonly introduced in kindergarten and first grade. Three foils and the correct choice are both written and pictured for each stimulus presentation. The total number of words for this 
section of the CRAIG is 33. The response form and answer sheet appear in Appendices $E$ and $F$.

A Beltone Masking Generator, meeting the calibration standards using the ISO 1964 levels endorsed by ASHA, was used to administer a speech masking noise of $65 \mathrm{~dB}$ SPL to all subjects.

\section{PROCEDURES}

\section{Screening Procedures}

The hearing screening was administered in a quiet room at the public school of the subjects. The room selected met the following requirements set forth by Pelson and Young (1984). The investigator, who has documented normal hearing, self administered a bilateral hearing screening at $15 \mathrm{~dB} H \mathrm{HL}$ for the frequencies of $500,1000,2000$, and $4000 \mathrm{~Hz}$. The investigator heard each frequency in both ears in order for the room to be acceptable for this study. Each subject was given a bilateral pure tone hearing screening at $20 \mathrm{~dB} H \mathrm{HL}$ for the frequencies of $500,1000,2000$, and $4000 \mathrm{~Hz}$ as per the 1988 OSHA standards. The subjects were required to respond to all frequencies in both ears in order to pass the screening. The hearing screenings were administered individually by the investigator.

The vision screening was administered in a well-1it room at the public school of the subjects. Each of the subjects stood 20 feet away from and faced the eye chart which was placed on a wall. The subjects were required to identify 
the position of 5 letters on the fifth line of the eye chart in order to pass the vision screening. The screening procedure tested bilateral vision. The vision screenings were done individually and all were administered by the investigator.

\section{Experimental Procedures}

The investigator administered the CRAIG in a quiet, well-lit room at the public school of the subjects. In addition to the room light, a small lamp was focused on the face of the investigator. The investigator did not wear lipstick for any of the presentations. Both the answer sheets and pencils were provided. The test was given to one subject at a time, and was presented live. All testing was completed in one session. Each subject was seated 4 feet directly across from the investigator and given the following instructions: "I'm going to say one word at a time, while you wear these headphones. You will hear noise coming out of the headphones, but you will not be able to hear my voice. Before each word I will hold up a number card so you will know what line of the answer sheet to look at. Look directly at me and watch closely, because I'm only going to say each word one time. We will do one practice item before I begin the test." The investigator then placed the headphones on each of the subjects.

The Beltone Masking Generator headphones placed on each subject emitted a masking noise of $65 \mathrm{~dB}$ SPL. According to 
J. F. Maurer (personal communication, December 1989), this amount of masking noise has no harmful effect on hearing. The amount of masking noise needed was determined during a pilot study conducted at Portland State University. One adult subject, hearing the masking noise, was given Form "A" of the CRAIG. The average frequency of the investigator's speaking voice was determined by a certified audiologist, using a sound level meter, to be $64 \mathrm{dBa}$ SPL with a range of 60-66 dBa SPL. When seated 4 feet from the investigator and hearing a masking noise of $65 \mathrm{~dB}$ SPL, the subject was unable to hear the investigator's voice. All subjects for this study were seated 4 feet from and directly across from the investigator.

Training and Reliability

\section{Procedures}

Prior to beginning the study, a pilot study was conducted in order to train the investigator in the test procedures and to establish test-retest reliability between the 2 single word forms of the CRAIG. Eight children, ranging in age from 6 to 11 years, were selected from the Portland Metropolitan area. All of these children met the same criteria as the subjects of the study, and all were given hearing and vision screenings. Form "A" of the CRAIG was given to 4 subjects and Form "B" to 4 subjects. Within 2 weeks, each subject was retested using the alternate form of the test. All testing was done in the private home of the child. The raw scores for each child are shown in 
Table II. The mean score determined for Form "A" was 21.25 and the mean score for Form "B" was 21.12 (Table III).

\section{TABLE II}

RAW TEST SCORES FOR FORMS "A" AND "B" OF THE CRAIG

\begin{tabular}{|c|c|c|c|c|}
\hline \multicolumn{2}{|c|}{ Form "A" } & \multicolumn{3}{|c|}{ Form "B" } \\
\hline Subject & Raw Score & subject & Raw & Score \\
\hline A & 15 & A & & 14 \\
\hline $\mathrm{B}$ & 17 & B & & 22 \\
\hline C & 22 & $\mathrm{C}$ & & 22 \\
\hline $\mathrm{D}$ & 25 & $\mathrm{D}$ & & 25 \\
\hline$E$ & 25 & $\mathrm{E}$ & & 19 \\
\hline $\mathrm{F}$ & 21 & $\mathrm{~F}$ & & 22 \\
\hline$G$ & 18 & G & & 22 \\
\hline $\mathrm{H}$ & 27 & $\mathrm{H}$ & & 23 \\
\hline
\end{tabular}

TABLE II I

MEAN SCORES AND STANDARD DEVIATIONS FOR FORMS "A" AND "B" OF THE CRAIG

\begin{tabular}{ccc}
\hline Form & Mean & SD \\
\hline "A" & 21.25 & 4.30 \\
"B" & 21.12 & 3.31 \\
\hline
\end{tabular}

As the mean scores for each of these forms of the CRAIG were within .13 of a point, the single word portion of the CRAIG appears to have high test-retest reliability. Form "A" was selected due to the slightly higher mean score obtained by the subjects chosen for the pilot study. 
SCORING AND DATA ANALYSIS

Scoring for the CRAIG is one point for each word correctly identified. The highest possible test score for the subtest given to the subjects in this study was 33 points. The mean score and standard deviation was determined for each group.

A one-tailed $\underline{t}$-test for independent means was calculated in order to determine whether or not there was a significant difference between the mean scores of the two groups. The level of confidence was set at .05 . 


\section{RESULTS}

This study was conducted to compare the speechreading ability of elementary school-age children with mild, moderate, and severe functional articulation disorders to children with normal articulation in order to determine if the two groups of children demonstrate the same degree of visual speech discrimination. The single word identification portion of the CRAIG, Form "A", was administered to the 25 experimental subjects and the 25 age-matched ( \pm 6 months) control subjects. The total score possible for this subtest is 33 points, one point for each item correctly identified. The resulting raw scores for the CRAIG, listed by age, for both the experimental and control groups are shown in Table IV. Table $V$ shows the mean score for each group by age level. The experimental group performed poorer than the control group with a mean score of $20.08(\mathrm{SD}=4.55)$ as compared with a score of $22.52(S D=3.05)$ for the controls. 
TABLE IV

RAW SCORES FOR THE CRAIG LIPREADING INVENTORY

\begin{tabular}{|c|c|c|c|}
\hline \multicolumn{2}{|c|}{ Control Group } & \multicolumn{2}{|c|}{ Experimental Group } \\
\hline Age & Score & Age & Score \\
\hline 6.06 & 21 & 6.05 & 10 \\
\hline 6.11 & 17 & 7.05 & 17 \\
\hline 7.02 & 23 & 7.06 & 18 \\
\hline 7.08 & 25 & 7.11 & 15 \\
\hline 8.02 & 23 & 8.03 & 15 \\
\hline 8.04 & 23 & 8.04 & 27 \\
\hline 8.05 & 23 & 8.06 & 26 \\
\hline 8.05 & 18 & 8.06 & 20 \\
\hline 8.06 & 22 & 8.10 & 23 \\
\hline 8.08 & 24 & 8.10 & 26 \\
\hline 8.09 & 17 & 9.00 & 19 \\
\hline 8.10 & 18 & 9.03 & 26 \\
\hline 9.02 & 24 & 9.04 & 21 \\
\hline 9.06 & 23 & 9.05 & 18 \\
\hline 9.07 & 29 & 9.06 & 22 \\
\hline 9.07 & 21 & 9.06 & 17 \\
\hline 9.09 & 27 & 9.08 & 21 \\
\hline 9.10 & 25 & 9.08 & 23 \\
\hline 10.01 & 20 & 9.10 & 19 \\
\hline 10.01 & 23 & 10.00 & 25 \\
\hline 10.02 & 20 & 10.02 & 19 \\
\hline 10.07 & 22 & 10.02 & 26 \\
\hline 10.08 & 26 & 10.07 & 20 \\
\hline 11.00 & 26 & 10.10 & 20 \\
\hline 11.03 & 23 & 11.00 & 13 \\
\hline
\end{tabular}


TABLE V

MEAN SPEECHREADING SCORES BY AGE GROUP

\begin{tabular}{lccc}
\hline \hline \multirow{2}{*}{ Group } & No. of Subj. & $\begin{array}{c}\text { Chron. Age } \\
\text { in Years }\end{array}$ & $\begin{array}{c}\text { Mean } \\
\text { Score }\end{array}$ \\
\hline \multirow{2}{*}{ Control: } & 1 & 6 & 21.0 \\
& 2 & 7 & 20.0 \\
& 6 & 8 & 22.3 \\
& 5 & 9 & 21.2 \\
& 8 & 10 & 23.4 \\
& 3 & 11 & 25.0 \\
Experimenta1 : & 1 & & 10.0 \\
& 2 & 6 & 17.5 \\
& 6 & 7 & 21.0 \\
& & 8 & 21.4 \\
& 5 & 9 & 21.5 \\
& 3 & 10 & 17.6 \\
\hline
\end{tabular}

A one-tailed $\underline{t}$-test for independent means was conducted to determine if there was a statistically significant difference between the mean scores of the CRAIG for the articulation disordered group $(\bar{x}=20.08)$ and that of the subjects with normal speech $(\bar{x}=22.52)$. The resulting $\underline{t}$-value of 2.22 indicates a statistically significant difference between the two groups on their speechreading abilities beyond the .05 level of confidence (Table VI). Thus the children with functional articulation disorders did not recognize the visual cues of speech as well as their normal speaking peers. 
TABLE VI

MEAN SCORES, STANDARD DEVIATIONS, AND $\underline{t}$-VALUES FOR COMBINED AGES

\begin{tabular}{lllll}
\hline \hline Group & Mean & SD & df & $t$ \\
\hline Control & 22.52 & 3.05 & & \\
Experimental & 20.08 & 4.55 & & $2.22 *$ \\
\hline
\end{tabular}

*Significant beyond the .05 level of confidence.

\section{DISCUSSION}

In this study, the ages of the subjects were generally older and more varied, ranging in age from 6 years, 5 months to 11 years, 3 months, than the subjects (who ranged in age from 5 years to 9 years, 10 months) used in the Russell (1971) study. Russell also used 5 subjects for each age group while this study had various numbers of subjects per age group. Despite these differences in subject age and number per group, the results shown by this study support those found by Russell.

Results of the Russell study also showed an improvement in speechreading skill as the age of the subjects increased. For this study, the Pearson Product Moment Coefficient of Correlation (Pearson $\underline{r}$ ) was utilized to determine the strength of the association between the age of the subjects and speechreading ability. The strength of the relationship depicted by the Pearson $\underline{r}$ is shown in Table VII. These results indicate that there was a slight correlation between 
increase in age and speechreading ability for the articulation-disordered group and a moderate correlation between these two factors for the normal speaking group.

TABLE VII

PEARSON $\frac{r}{r}$ COEFFICIENT OF CORRELATION BETWEEN
AGE AND SPEECHREADING SKILL

Group

Pearson $\underline{r}$

Control

Experimental

To determine the actual amount of overlap between the paired variables of increase in age and speechreading ability in terms of shared variance, the Coefficient of Determination was calculated by squaring the correlation coefficient $\left(\underline{r}^{2}\right)$. The results indicate that improvement in speechreading ability due to increase in age could be predicted about $5 \%$ of the time for the articulation disordered group and $28 \%$ of the time for the normal speaking group (Table VIII). Children's articulation normally improves with age and these results appear to support the importance that increased awareness of the visual speech cues may have on correct speech production for an older child. However, due to the varying numbers of subject per age in each of these groups, these results should be viewed with caution. 
TABLE VIII

COEFFICIENT OF DETERMINATION

\begin{tabular}{lcl}
\hline \hline Group & Pearson $\underline{\underline{r}}$ & $\underline{\underline{r}}^{2}$ \\
\hline Control & .53 & .2809 \\
Experimental & .22 & .0484 \\
\hline
\end{tabular}

None of the subjects in this study recognized all 33 items presented. This could be due to the homophemes, words which appear identical in production, that are included in the CRAIG. In addition, the children in the experimental group aged 8.03 to 9.03 did better on the CRAIG than their counterparts in the control group. The mean score for these ages was 21 for the control group and 23 for the experimental group. Reasons for this could be reading ability or comfort with the testing procedure.

The majority of the experimental subjects chosen for this study had moderate articulation disorders, with 3 subjects being diagnosed as mild, and 1 being diagnosed as severe by the speech-language pathologist at their public school. Severity of disorder did not appear to affect the speechreading ability of these subjects as the respective scores for these subjects were 14, 25, 20, and 23. There were more males than females in both groups and while this was not a control factor in this study, no difference in speechreading ability between sexes was noted. The majority of all subjects stated that they enjoyed taking the test and 
that it was "fun to try to read lips." Many of the children asked to do it a second time, and none appeared overly concerned about having their speechreading skill being tested. Several children did express relief at passing the hearing screening, however.

The speechreading test used in this study was presented live on a one-to-one basis with each subject. The variability of live presentation has been addressed by O'Neill and Oyer (1981). While it is impossible to state that there was no variation in this investigator's live presentation of the CRAIG, several procedural controls were implemented to assure consistency. The masking noise, distance from the speaker, and the lighting were controlled in each public school where the testing was done. This investigator did not wear lipstick or earrings and wore the same hair style for each presentation at each school. All the tests were administered in a quiet room with only the speaker and the subject in attendance. Twenty-eight subjects ( 14 experimental and 14 control), who attended the same public schools, were tested in the morning and the remaining 22 subjects were tested in the afternoon. Testing times were determined by the public school principals. Therefore, despite the problems inherent in live presentation of speechreading tests, the procedural controls implemented for this study give this investigator confidence in the results obtained.

The importance that the visual cues of speech may have on correct speech production was established by Woodward and 
Barber (1960) in their landmark study. Binne, Montgomery, and Jackson (1974) also found that visual discrimination is most important in determining place of articulation and that this determination may also influence correct speech production. The results of this study support these findings. Mills (1983) and Dodd (1983) compared the articulation of visually impaired children with that of normal seeing peers. These researchers found that, with regard to place of articulation, the children with visual handicaps had both more and varied articulation errors. Dodd noted that the information received visually shows a child how to produce a sound. The results of this study also appear to support Dodd's findings.

While it cannot be stated that speechreading ability is a predictor of correct speech production, the results of the present study and others cited in this paper suggest that the visual perception of speech may be a contributing factor to correct articulation. Visual discrimination of speech can be easily and quickly evaluated by using a speechreading test, and this information could be valuable when working with a child who has an articulation disorder. 


\section{CHAPTER V}

\section{SUMMARY AND IMPLICATIONS}

\section{SUMMARY}

The purpose of this study was to compare the speechreading abilities of elementary school-age children with mild to severe articulation disorders with those of children with normal articulation. Speechreading ability, as determined by a speechreading test, indicates how well a person recognizes the visual cues of speech. Speech sounds that have similar visual characteristics have been defined as visemes (Jackson, 1988) and can be categorized into distinct groups based on their place of articulation. A relationship between recognition of these visemes and correct articulation was first proposed by Woodward and Barber (1960). Dodd (1983) stated that speechread information shows a child how to produce a sound, while aural input simply offers a target at which to aim.

Fifty subjects participated in this study, 25 children with normal speech, and 25 children with functional articulation disorders. All were chosen from the greater Portland Metropolitan area. To qualify for inclusion in this study all subjects had normal vision, hearing, and intelligence. The experimental group was selected first and the control 
group was then individually age-matched to this group within \pm 6 months. All subjects wore headphones emitting $65 \mathrm{~dB}$ SPL of masking noise while being given the Craig Lipreading Inventory (CRAIG) which was administered live by the investigator.

Statistical analysis using a one-tailed $\underline{t}$-test for independent means was conducted to compare the groups. A statistically significant difference beyond the .05 level of confidence was determined, with the children in the control group performing better than those with articulation disorders. These results indicate that children with articulation disorders do not recognize the visual speech cues as well as their normal spealsing peers. These results agree with those of a similar study done by Russell (1971). The implications of this study suggest that recognition of the visual speech cues may contribute to correct speech production and perhaps teaching speechreading along with articulation treatment would be helpful for some children with functional articulation disorders.

\section{IMPLICATIONS}

\section{$\underline{\text { Research }}$}

One research implication suggested by the results of this study would be to assess the speechreading ability of children between 3 and 5 years of age. This study, as well as the one done by Russell (1971), used children who were enrolled in public schools. However, as preschool children 
also exhibit articulation disorders and many receive treatment for these disorders, a study designed to test the speechreading ability of these younger children could provide valuable information. The method of recording responses of younger children, as well as training them to the task, may prove difficult.

In addition to testing younger children, assessment of the speechreading ability of children with severe articulation disorders and/or multiple articulation errors could provide additional information about these disorders. Severity of the articulation disorder was not a factor in the speechreading ability of the subjects for this study.

Besides age and severity of disorder, research using different types of speechreading tests could be conducted. This study, and the one conducted by Russell in 1971, used word recognition tests only. Perhaps the children with articulation disorders would perform better in sentence or story recognition tests, as connected speech is more meaningful and is more representative of normal speech.

\section{Clinical}

Clinical implication questions raised by this study include a need to compare remediation programs between children having fundamentally auditory programs to those children receiving visual programs. The primary method of traditional articulation treatment is an auditory stimulation approach. However, many children remain in articulation treatment 
several years undergoing this same remediation method. Would a treatment stressing visual recognition of phonemes be more beneficial for some of these children? In addition, should a speechreading assessment be included when evaluating the speech production of articulation disordered children? If a child showed poor ability to recognize visual speech cues, then should this ability be enhanced through instruction or should it be avoided and the auditory or motor method stressed instead?

When considering these questions, another clinical implication is raised. Should a child with articulation disorders be taught speechreading techniques independent of speech remediation? Speechreading is a skill that can not only be improved with training, but also through practice (Warren, Dancer, Monfils, and Pittenger, 1989). If this procedure were used, would it be more appropriate for children who are on self-monitoring for their articulation errors? Would this be a program to use with children beginning treatment, or with children within a certain age group? The questions raised by the results of this study are intriguing. Assessing or teaching speechreading to children with articulation disorders may never become an accepted treatment approach; however, clinicians need to be open to novel treatment ideas in order to plan the best program for each individual with whom they work. 
REFERENCES

Alpiner, J. G. and McCarthy, P. A. (1987). Rehabilitative audiology: Children and adults. Baltimore: Williams \& Wilkins.

Berger, K. W. (1972). Speechreading principles and methods. Baltimore: National Educational Press.

Binne, C. A., Montgomery, A. A., and Jackson, P. L. (1974). Auditory and visual contributions to the perception of consonants. Journal of Speech and Hearing Research. $17,619-630$.

Craig, W. N. (1964). Effects of preschool training on the development of reading and lipreading skills of deaf children. American Annals of the Deaf, 109, 280-296.

Crawford, J., Dancer, J., and Pittenger, J. (1986). Initial performance level on a speechreading task as related to subsequent improvement after shortterm training. The Volta Review, 88, 101-105.

Dent, L. J., Huntington, D. A., and Schubert, E. D. (1982). American English medial consonant test. Manuscript, Stanford University, Palo Alto, CA.

Dodd, B. (1977). The role of vision in the perception of speech. Perception, $\underline{6}, 31-40$.

(1983). The visual and auditory modalities in phonological acquisition. In A. E. Mills (ed.), Language acquisition in the blind child, pp. 57-61. Beckenham, Kent, England: Croom Helm, LTD.

(1987). The acquisition of lip-reading skills in normally hearing children. In $B$. Dodd and $R$. Campbell (eds.), Hearing by eye: The psychology lip-reading, pp. 163-176. Hilisdale, NJ: Lawrence Erlbaum.

Dodd, B. and Burnham, D. (1988). Processing speechread information. The Volta Review, 90, 41-61.

Dodd, B. and Campbell, R. (1984). Non-modality specific speech coding: The processing of lip-read information. Australian Journal of Psychology, 36, 171-179. 
Elstner, B. (1983). Abnormalities in the verbal communication of visually impaired children. In A. E. Milis (ed.), Language acquisition in the blind child, pp. 1841. Beckenham, Kent, England: Croom Helm, LTD.

Fisher, C. B. (1968). Confusions among visually perceived consonants. Journal of Speech and Hearing Research, 11, 796-804.

Haas, W. H. (1982). Stimulus predictability and speechreading performance. The Volta Review, $82,156-162$.

Jackson, P. L. (1988). The theoretical minimal unit for visual speech perception: Visemes and coarticulation. The Volta Review, 90, 99-115.

Jeffers, J. and Barley, M. (1971). Speechreading (1ipreading). Springfield, IL: charles C. Thomas.

Kricos, P. B. and Lesner, S. A. (1982). Difference in visual intelligibility across talkers. The Volta Review, 84, 219-225.

MacDonald, J. and McGurk, M. (1978). Visual influences on speech perception processes. Perception \& Psychophysics, 24, 253-257.

Mills, A. E. (ed.) (1983). Acquisition of speech sounds in the visually-handicapped child. In Language acquisition in the blind child, pp. 46-56. Beckenham, Kent, England: Croom Helm, LTD.

O'Neil1, J. J. and Oyer, H. (1981). Visual communication for the hard of hearing. Englewood Cliffs, NJ: Prentice-Hall, Inc.

Owens, E. and Blazek, B. (1985). Visemes observed by hearing-impaired and normal-hearing adult viewers. Journal of Speech and Hearing Research, 28, 381-393.

Pelson, R. O. and Young, N. B. (1984). Hearing conservation in the schools: A program quide. Portland, OR: Oregon State Health Division.

Russe11, N.E. (1971). Speechreading ability in children with functional articulation difficulty and in children with normal articulation. Manuscript, Portland state University, Portland, OR.

Spelke, E. (1976). Infants' intermodal perception of events. Cognitive Psychology, 8, 553-560. 
Utley, J. (1946). A test of lipreading ability. The Journal of Speech Disorders, 11, 109-116.

Warren, Y., Dancer, J., Monfils, B., and Pittenger, J. (1989). The practice effect in speechreading distributed over five days: Same versus different CID sentences 1ists. The Volta Review, 91, 321-325.

Weiss, C. E., Gordon, M. E., and Lillywhite, H. S. (1987). Clinical management of articulatory and phonologic disorders. Baltimore: Williams \& Wilkins.

Woodward, M. F. and Barber, C. G. (1960). Phoneme perception in lipreading. Journal of Spech and Hearing Research, $\underline{3}, 212-222$. 
APPENDIX A

\section{INTRODUCTORY LETTER}

Dear Parent,

As a parent of a second grader at Park Place Elementary Schoo1, I share your concern when a graduate student requests permission to study our children. However, as a graduate student needing children for my study, I need your help.

Allow me to introduce myself. I am a mother and a second year graduate student at Portland State University. My husband and I have owned a home in the rural oregon City area for the past 8 years. Five years ago I went back to school to earn my degree in speech pathology. My goal is to work with children that have special needs in the area of speech and language development. The study I am now doing is part of my thesis, which is the final step toward my degree.

I appreciate your consideration in this matter. If you have any questions or concerns, please feel free to call me at 655-5483. Thank you. 


\title{
APPENDIX B
}

\author{
CONSENT FORM FOR SUBJECTS AND CONTROLS
}

\section{Dear Parent,}

I am a graduate student at Portland State University in the Speech and Hearing Sciences Program. I am investigating the lipreading or speechreading ability of elementary school-aged children. I would appreciate your permission for your child to participate in my study.

In this study each child will be given a hearing and vision screening test. Then they will be asked to identify 33 words that are read to them by marking their answer on a multiple choice test form. Each child will wear headphones which will emit just enough noise to block out my voice. There is no risk to your child if he/she participates in the study. These procedures should take about 15 to 20 minutes.

I will be supervised by Mary E. Gordon, Associate Professor at Portland State University. Your child's name will not be used in this study. You or your child may not receive any direct benefit from participation in this study, but participation could help increase knowledge which would benefit others in the future. You may withdraw your child from this study at any time without penalty and without jeopardizing any relationship you may have with Portland State University or your child's school system.

Please return this form to your child's teacher. Thank you for your consideration.

$$
\text { Barbara Habermann }
$$

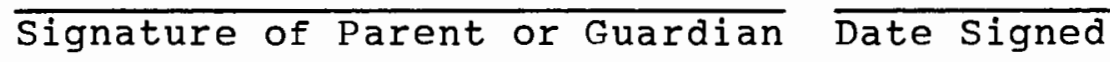

If you experience problems that are the result of your participation in this study, please contact the secretary of the Human Subjects Research and Review Committee, Office of Grants and Contracts, 303 Cramer Hall, Portland State University, 725-3417. 
APPENDIX C

CONSENT FORM FOR SUBJECTS OVER 7 YEARS OF AGE

Dear Student,

My name is Barbara Habermann and I am a graduate student at Portland State University. I am doing a study on how well elementary school students can lipread words. I would like your permission to participate in my study.

For my research I will test your hearing and vision. I will also have you identify words that I say while you are wearing headphones that give out just enough noise so you can't hear my voice. You will mark what you think the word is with an " $X$ " on an answer sheet I will give you. This test will not affect your grade at school in any way.

My teacher at Portland State is Mary E. Gordon and she will supervise me. I will not use your name in this study. It is always your right to change your mind about being in my study, and no one will be angry.

Please return this form to your teacher. Thank you for your consideration.

Barbara Habermann

Signature of child

Date Signed

Child's Full Name

Child's Birthdate

If you experience problems that are the result of your participation in this study, please contact the secretary of the Human Subjects Research and Review Committee, Office of Grants and Contracts, 303 Cramer Hall, Portland State University, 725-3417. 
APPENDIX D

GRAHAM-FIELD EYE CHART
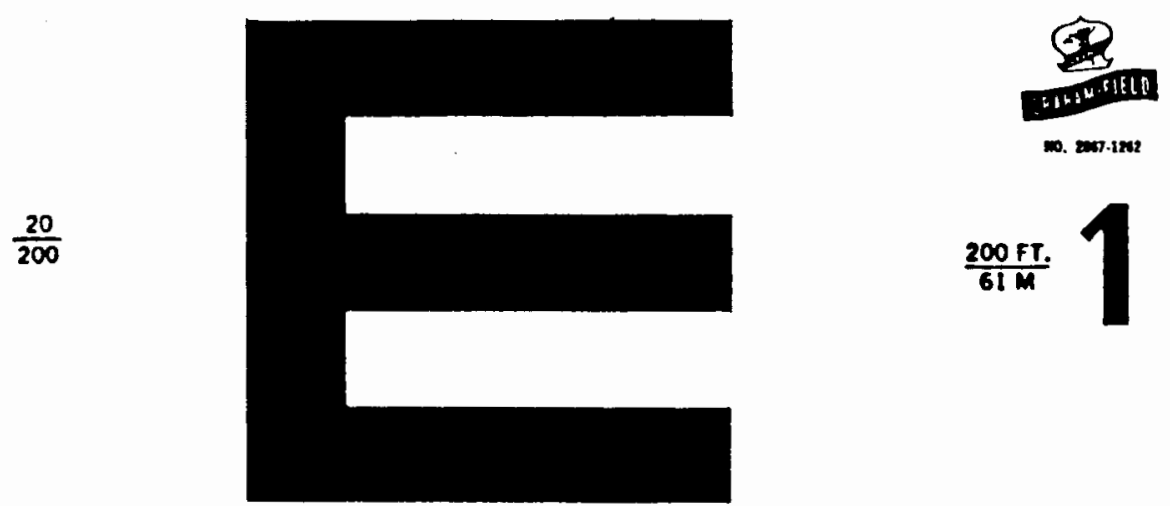

๓. 201.1\%2 $\frac{200 F T .}{61 M}$
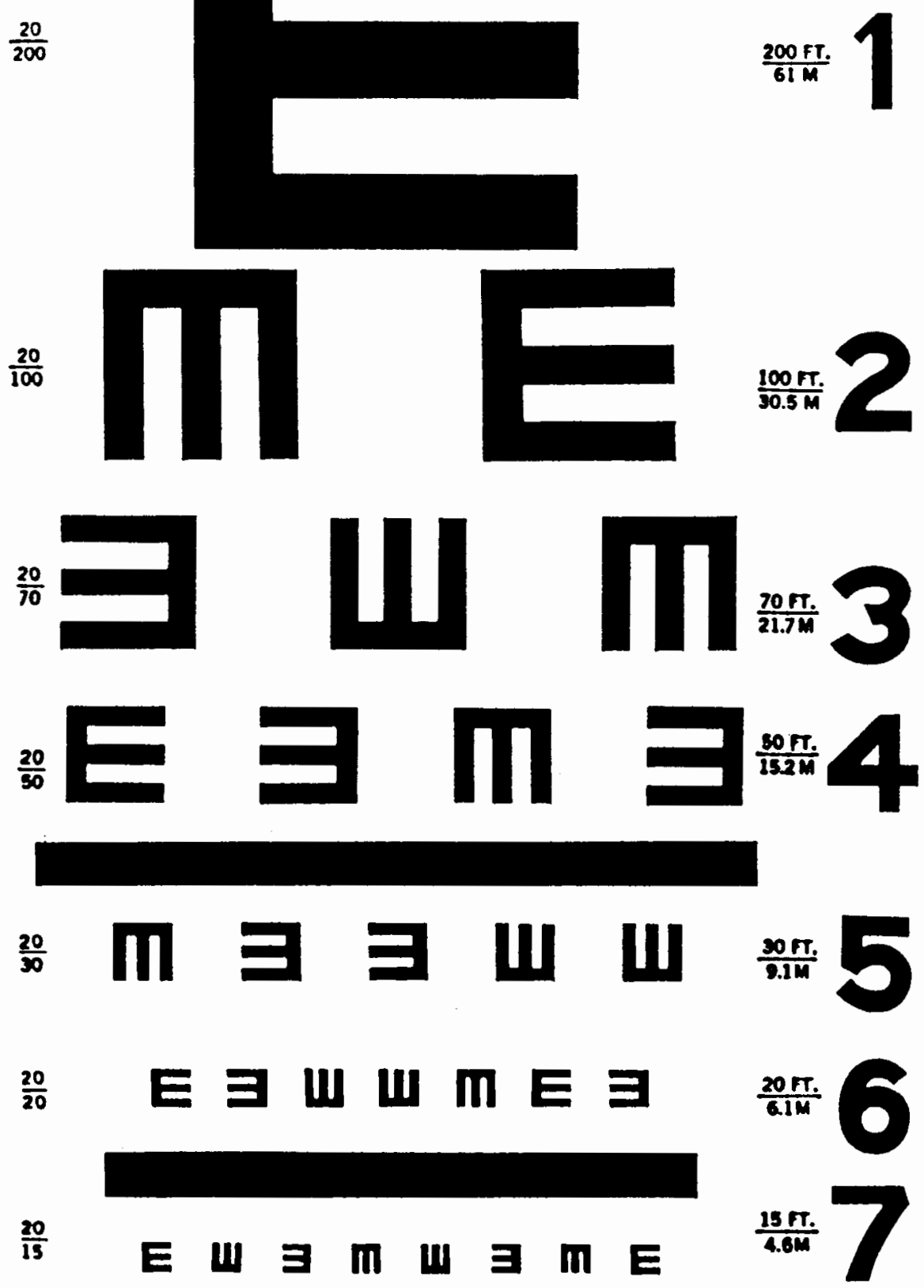


\section{CRAIG LIPREADING INVENTORY}

Wond Recognition

NAME:

AGE:

DATE:

SCHOOL:

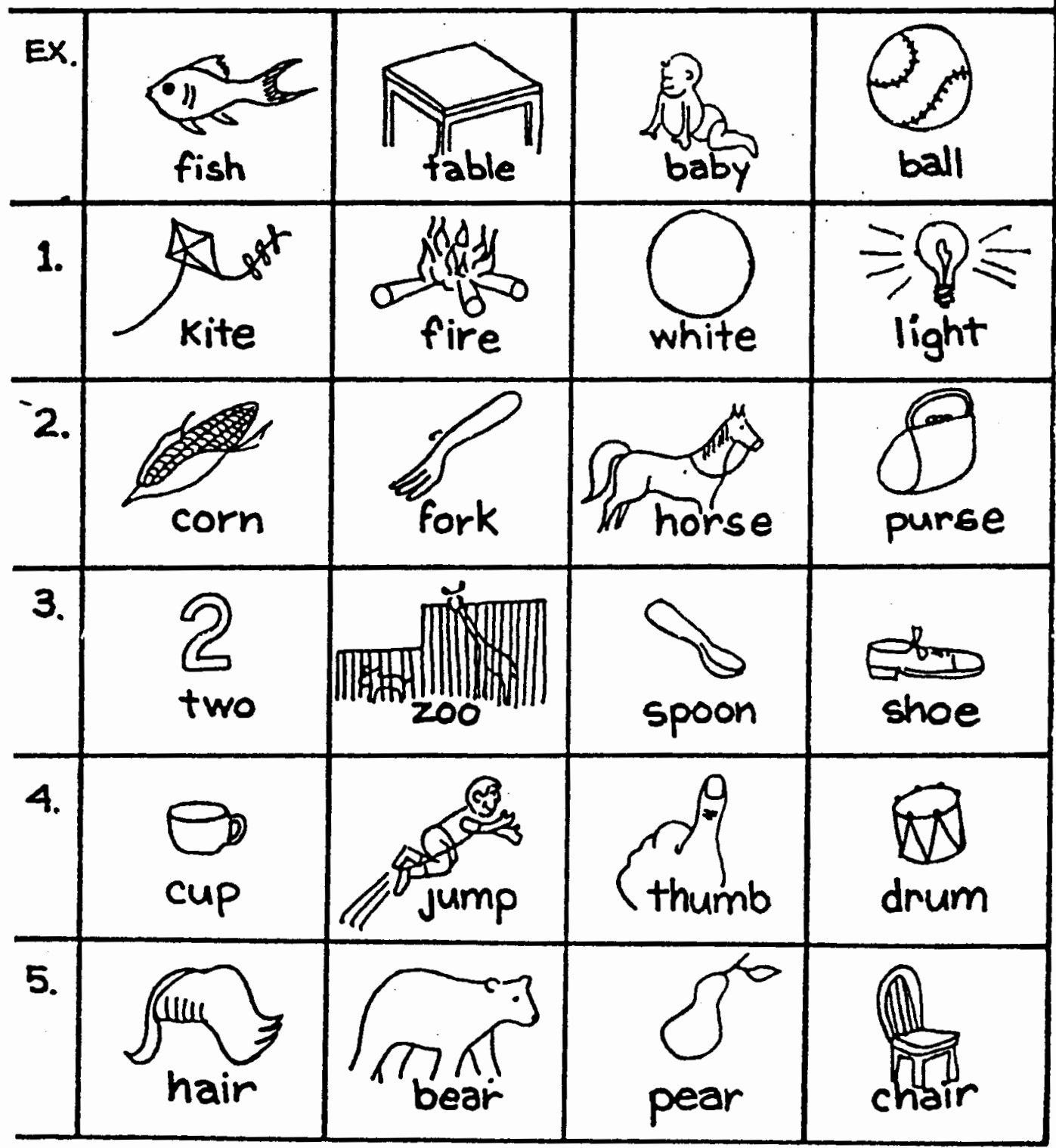


WORD RECOGNITION

PASE 2.

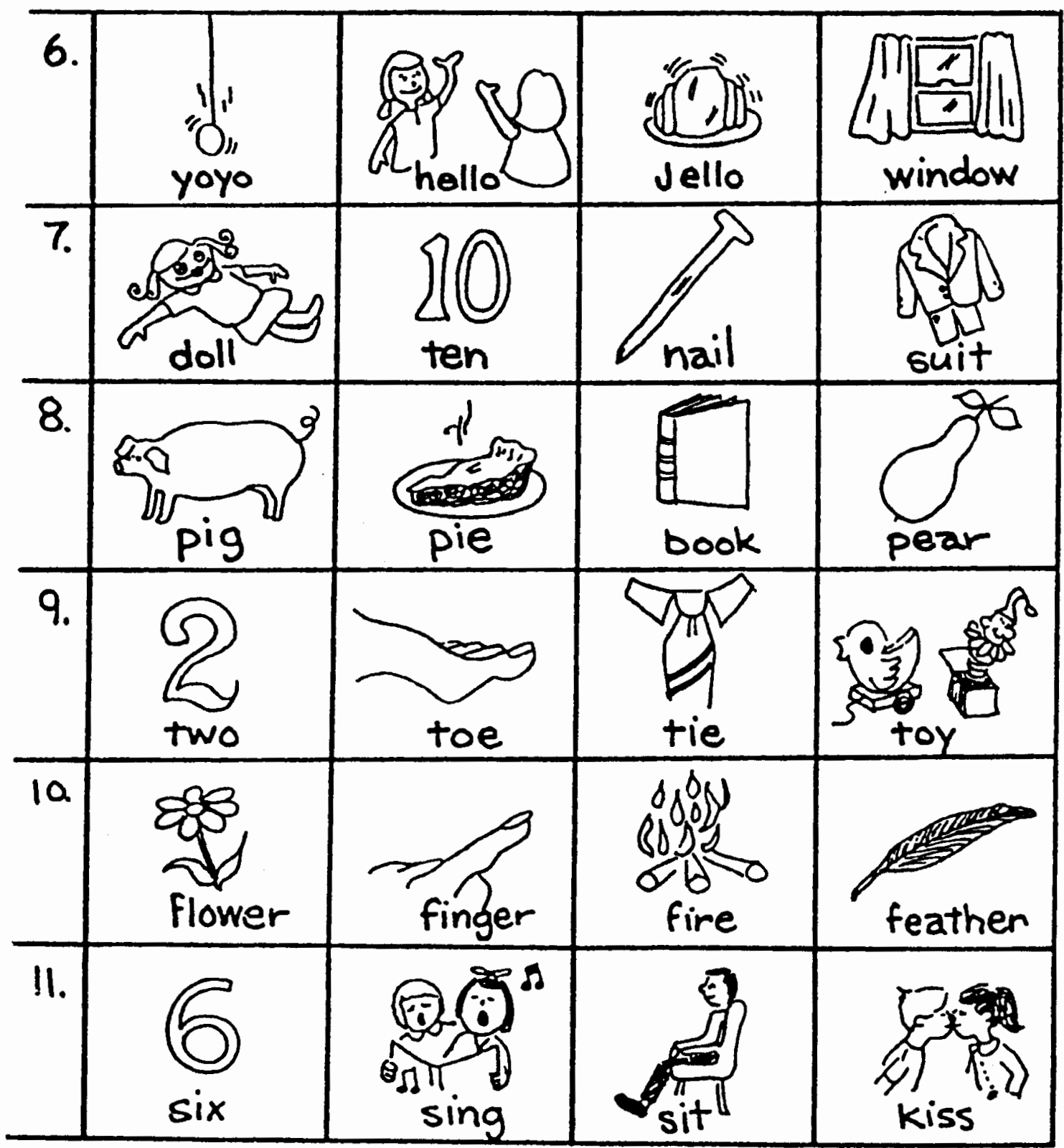


WORD RECOGNITION

PAGE 3.

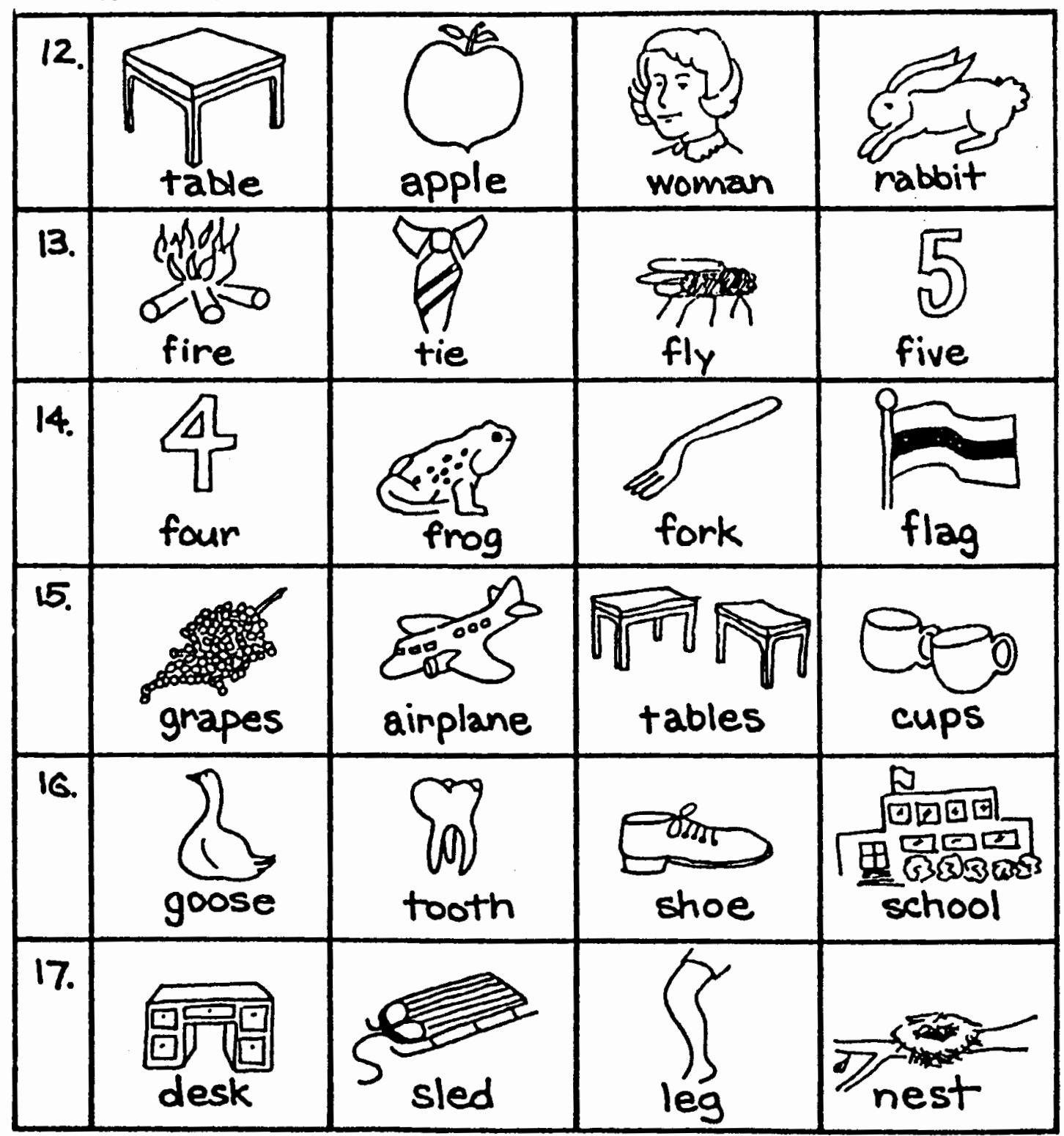




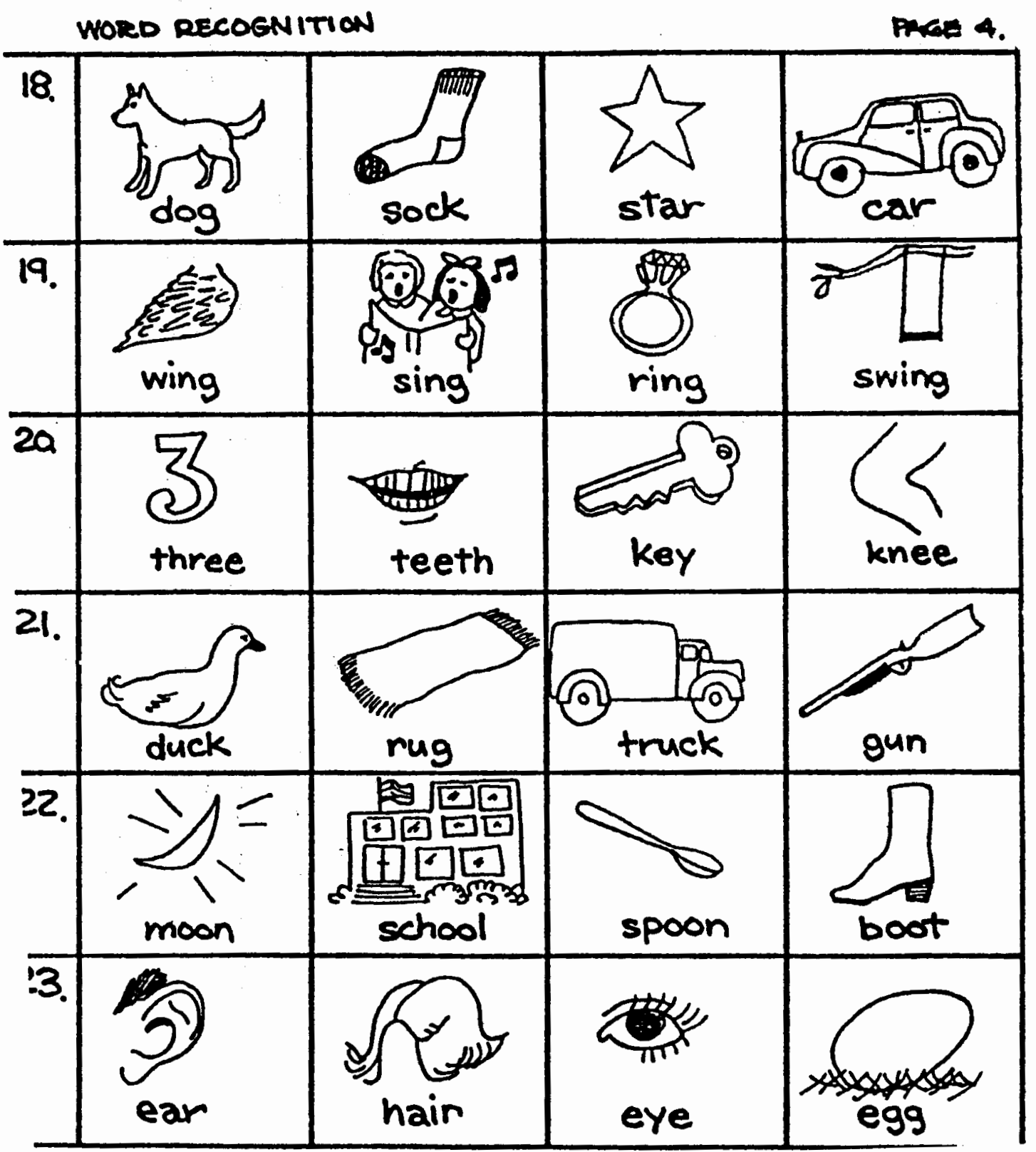


WORD RECOENITION

PACE 5.

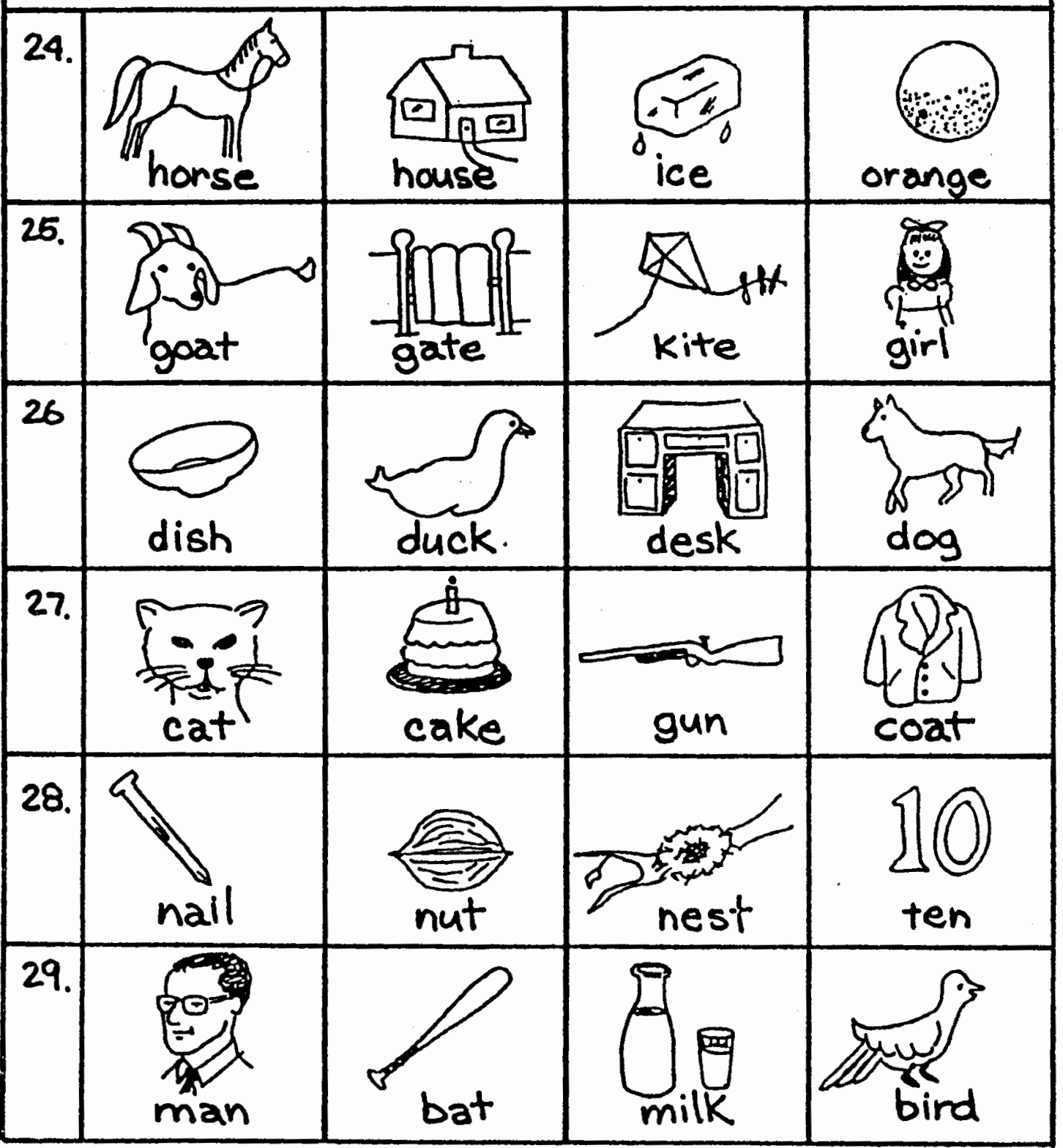




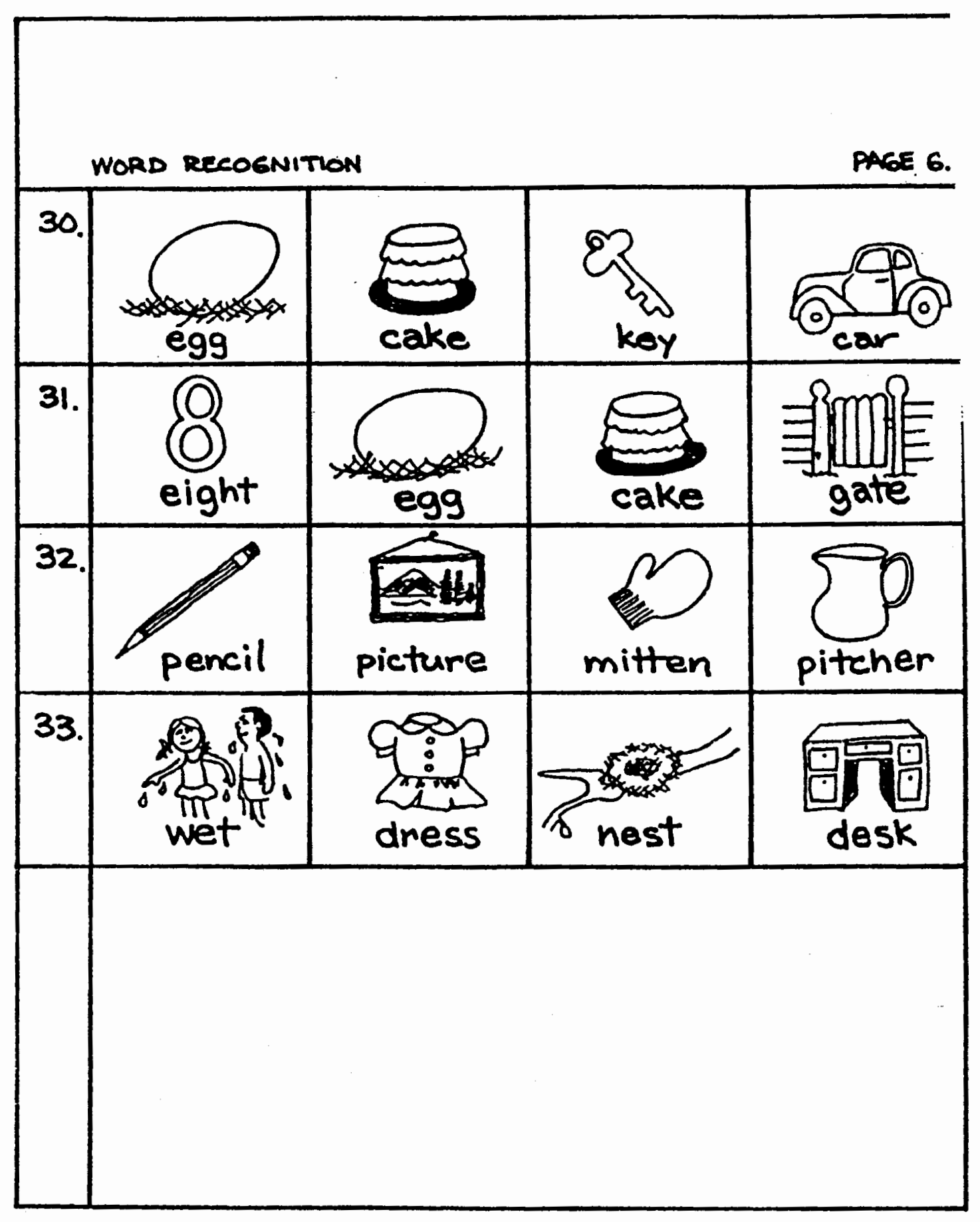




\section{APPENDIX F \\ ANSWER SHEET FOR FORM "A" OF THE CRAIG \\ LIPREADING INVENTORY}

\begin{tabular}{|c|c|c|c|c|}
\hline 1. White & 12. & Woman & 23. & Ear \\
\hline Corn & 13. & $\mathrm{~F} 1 \mathrm{y}$ & 24 . & Ice \\
\hline Zoo & 14. & Frog & 25 . & Goat \\
\hline Thumb & 15 . & Grapes & 26 . & Dog \\
\hline Chair & 16. & Goose & 27 . & Cat \\
\hline Je110 & 17. & sled & 28 . & Nut \\
\hline Dol1 & 18. & star & 29 . & Milk \\
\hline Pig & 19. & Sing & 30. & Cake \\
\hline Toy & 20 . & Three & 31. & Eight \\
\hline Finger & 21 . & Duck & 32 . & Pencil \\
\hline Six & 22 . & Spoon & 33. & Desk \\
\hline
\end{tabular}

